\title{
BEHAVIOUR OF METALS - PROBLEM FOR HEAT TRANSFER FROM THE AUTOMOBILE BRAKES SYSTEMS
}

\author{
Porag Kalita ${ }^{1}$ \\ ${ }^{1}$ Head of Automobile Engineering Department, Vocational Education (+2), M R S Higher Secondary School, Titabor, \\ Jorhat, Assam, India - 785630
}

\begin{abstract}
We know that, The Braking action is the use of a controlled force to reduce the speed or to stop a moving vehicle or to keep a vehicle stationary, when braking is applied, it develop friction which does the braking i.e. Kinetic energy which is converted into heat energy on the application of brake.
\end{abstract}

The biggest question today is, while the driver is going to brake applied, this force is increasing by 8 times of as per horse power. For example, one vehicle has $100 \mathrm{hp}$, after the braking applied is going to reached $800 \mathrm{hp}$. Therefore, in terms of behavior of metals, some time frequent accident by means of dragging. Because, this heat is transferred through the surrounding air.

The weight of the vehicle is divided on its axle, and retarding force acts on the point of road contacts towards the rear and the inertia force of gravity towards the font. Let $F=$ retarding force, $\mu=$ coefficient of friction, $W=$ weight of the vehicle, $h=$ height of centre of Gravity of the vehicle from road. Therefore,

$F=\mu W($ inertia force) and couple $=\mu W \times h$

Keywords: Braking action, horse power, inertia

\section{INTRODUCTION}

The braking system is an important part of the automobile. The main objective of the brake system is to stop the vehicle within the smallest possible distance or to reduce speed whenever is required

Classification of brake system as follows:

1. In terms of application:
(a) Foot Brake,
(b) Hand Brake

2. In terms of application on wheels:
(a) Two Stroke wheel ( motorcycle)
(b) Four stroke wheel (car/LCV/HCV)

3. In terms of force in braking contact:
(a) Internal Expanding Brakes,
(b) External Expanding Brakes.

4. In terms of applying the braking force:
(a) Single acting brakes.
(b) Double acting brakes.

5. In terms of brake gear:
(a) Mechanical Brakes
(b) Power Brakes.

6. In terms of the nature of power employed:
(a) Vacuum Brakes,
(b) Air Brakes.
(c) Hydraulic Brakes,
(d) Electric Brakes,
(e) $\mathrm{DAOH}$ etc.

The terms of braking system, we may define the following way:

$$
\mathbf{P}=\mathbf{m f}=\mathrm{w} / \mathrm{g} \times \mathbf{f}(\mathbf{a s} \mathbf{m}=\operatorname{mass}=\mathrm{w} / \mathrm{g})
$$

Here, $\mathbf{P}=$ Force on the vehicle,

$\mathrm{W}=$ weight of the vehicle,

$\mathrm{g}=$ acceleration due to gravity .

$\mathbf{f}=$ vehicle acceleration $\left(\operatorname{as~} \mathbf{m} / \mathrm{s}^{2}\right)$.

The application of declaration /negative declaration force is:

$$
\mathrm{P}=\mu \mathrm{W},
$$

Here, $\mu=$ coefficient of friction,

However, $\mathrm{P}=\mathrm{W} / \mathrm{g} \times \mathrm{f}$,

Therefore, $\mathrm{f}=\mu \mathrm{g}$.

For the Time taken at a steady speed of $\mathrm{V} \mathrm{m} / \mathrm{s}$, which is rate of deceleration being $\mu \mathrm{g}$ :

Therefore, $\mathbf{t}=\mathbf{V} / \boldsymbol{\mu g}$

Hence stopping velocity distance $=$ mean velocity $\times$ time $=$ $\mathrm{V} / 2 \times \mathrm{V} / \mu \mathrm{g}=\mathrm{V}^{2} / 2 \mu \mathrm{g}$.

Let $\mu=0.6, \mathrm{~g}=9.81 \mathrm{~m} / \mathrm{s}^{2}$.

Here stooping distance $=V^{2} / \mathbf{2} \times \mathbf{6} \times \mathbf{9 . 8 1}$ 
Thus we infer that stopping distance increase with vehicle speed, which is depending on good braking action.

\section{LITERATURE REVIEW:}

\subsection{Braking Action:}

The braking action is the use of a controlled force to reduce the speed or to stop a moving vehicle or to keep a vehicle stationary, when braking force is applied, it develop friction which does the braking friction is the resistance to motion between two surfaces, thus by forcing a stationary surface into contact with moving surface, the resistance to the relative motion or the rubbing action between the two surfaces will slow down the vehicle.

While the vehicle speed is increase, require the increase in the braking action to bring moving vehicle to a stop. A moving vehicle has a Kinetic energy, this energy increases with square of speed and must be overcome by braking action, as such if vehicle speed is doubled, its kinetic energy is increased fourfold, with this 4 times braking action would be required to stop such vehicle.

Brakes must not only stop the moving vehicle but stop it in shortest possible distance. As such brakes must decelerate the vehicle at a faster rate than the engine can accelerate it. For this the brakes must be designed to control greater power than the developed by the engine. A rough comparison between the horse power developed by the engine and the horse power controlled by the brakes.

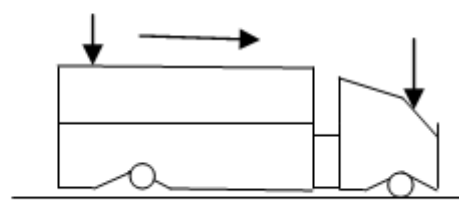

(a)

Fig: Steady Speed:

(A car travelling at steady speed has its weight evenly distributed)
With the vehicles possible to accelerate of $90 \mathrm{HP}$ from standing position to gain a speed of $100 \mathrm{kmph}$ in 40 seconds, now in case we have to stop such vehicle at speed of $120 \mathrm{kmph}$ to a full stop it should not take more than 4.5 seconds. From the above example you would have seen that time required to decelerate to a stop is one eight the time required to accelerate from standing start. Hence, the brake must handle eight times the power developed by the engine, in this case it should be $90 \times 8=720 \mathrm{HP}$ which the brakes have to develop to bring the vehicle to a stop from 120 kmph in 4.5 seconds.

While we going to applied brakes, the wheel will either roll or skid depending upon the relative value of friction between braking surface in between tyre and road. Therefore, the brakes are designed to take care of load distribution. When brakes are applied as a hard braking there is greater transfer of weight and rear wheel tend to lock which often causes the tail of the car to slide sideway ( Dragging), if the front wheel becomes locked first, the vehicle will usually slide straight and as such brakes are designed in such a way that maximum braking effort can be applied to the rear wheel beyond this limit extra Pedal pressure acts on front brakes only.

\section{METHODOLOGY}

The principal of Hydraulic Brakes system, "to bring to stop, its kinetic energy must be changed into heat energy. The amount of pedal pressure is approximately 20 to $50 \mathrm{~kg}$. To transmit the pedal pressure equally to each wheel, Pascal's is applied.

We know, that hydraulic fluid transits pressure equally to all brake shoes based on Pascal's Law which states that, " When any part of a confined fluid is subjected to pressure, the pressure is transmitted equally and undiminished to every portion of the inner surface of that container.
For example, a pedal effort of $25 \mathrm{~kg}$ applied by the driver on the brake pedal is multiplied by a leverage of $23 \mathrm{~cm}$ giving $(25 \times 23=575 \mathrm{kgf})$ on to the master cylinder piston. Let the master cylinder piston be of area $5 \mathrm{~cm}^{2}$ then a pressure of $575 / 5=115 \mathrm{~kg} / \mathrm{cm}^{2}$ is transmitted equally to the entire four wheel cylinder in accordance with Pascal's law.

\subsection{Hydraulic Brake System}

Hydraulic brake systems are operated by brake fluids i.e. liquid pressure. The brake fluids directly pressurized on the wheel cylinder as well as brake shoes, by the application of brake pedal force. The main advantages that it applies equal pressure on the entire four wheels. As per Pascal's Law which states that when any part of a confined the pressure is 
transmitted equally and undiminished to every portion of the inner surface of that container. As per formula, (Example) pedal efforts of $30 \mathrm{~kg}$, applied by the driver on the brake pedal and by a leverage of $25 \mathrm{~cm}(30 \times 25=75$ kgf) on the Master cylinder Piston and as per Pascal's transmitted equally to all two wheels.
The Hydraulic Brake is consists by the following:

1. Master Cylinder, 3. Wheel cylinder,

2. Brake Lining, 4.Returning spring, etc.

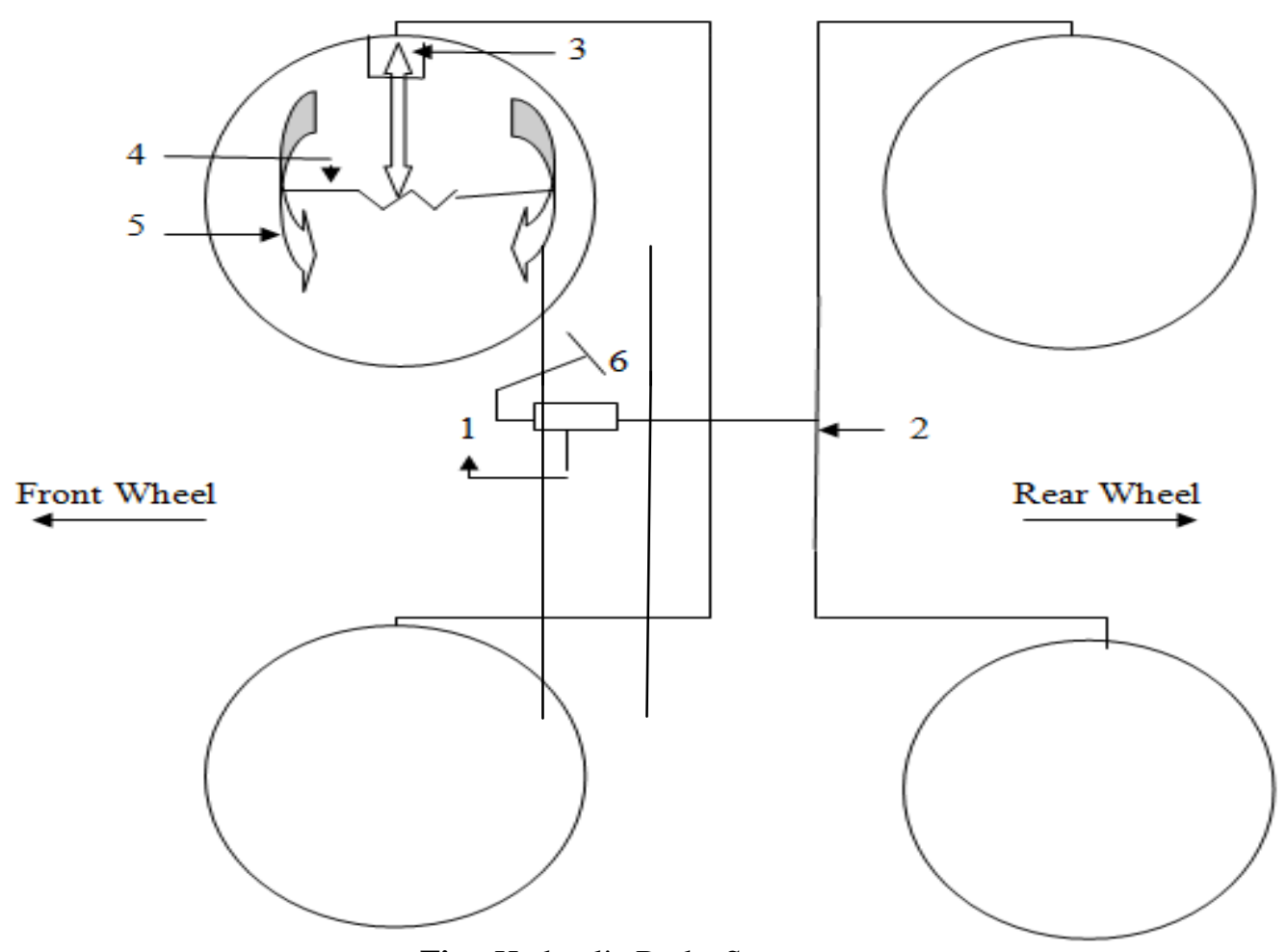

Fig : Hydraulic Brake System:

While the driver pressed on the brake pedal by foot, the brake fluids from the master cylinder goes to contact the wheel cylinder through brake linings. While brake fluids pressed on the wheel cylinder, the returning spring getting expansion and directly acting on the brake shoes and the brake shoes contact the drum on the wheel, and this position is called brake engaged. While the driver release the foot from the brake pedal, the said brake fluids comes back to the master cylinder and this position is called brake disengaged. In generally, the service brakes are operated by Pedal i.e. controlled by pedal itself, and the parking brakes which is controlled by a hand lever, which is available near the driver cabin and action is directly acting on the rear wheels. The parking hand brake must be using a normal braking, which is means that only emergencies action.

\section{RESULT}

\subsection{Example by Problem}

(Determine the weight transferred from rear wheels to front wheels for a passenger car with wheel base equal to free times the height of centre gravity of the vehicle above the ground, If the brakes are applied to all four wheels to utilize all the road friction available ( all wheels at impending ). Assume $\mu=0.7$.

\section{Answer:}

On level road, the static weight distribution on the rear wheel,

$$
R_{B}=m, W=m w / w, W=m w \times 5 / h . W
$$

Where, $R_{B}=$ Static level road reaction on rear wheel.

For four wheel brakes, all at impending slide,

$$
\mathbf{f}=\mu \mathbf{t} \times \mathbf{g}
$$

Taking moments about front wheel and road contact point, We have,

$$
\mathbf{R}^{1}{ }_{B} \times \mathbf{w}+\mathbf{w} / \mathbf{g} \mathbf{f} . \mathbf{h}-\mathbf{W}(\mathbf{m} . \mathbf{w})=\mathbf{0}
$$




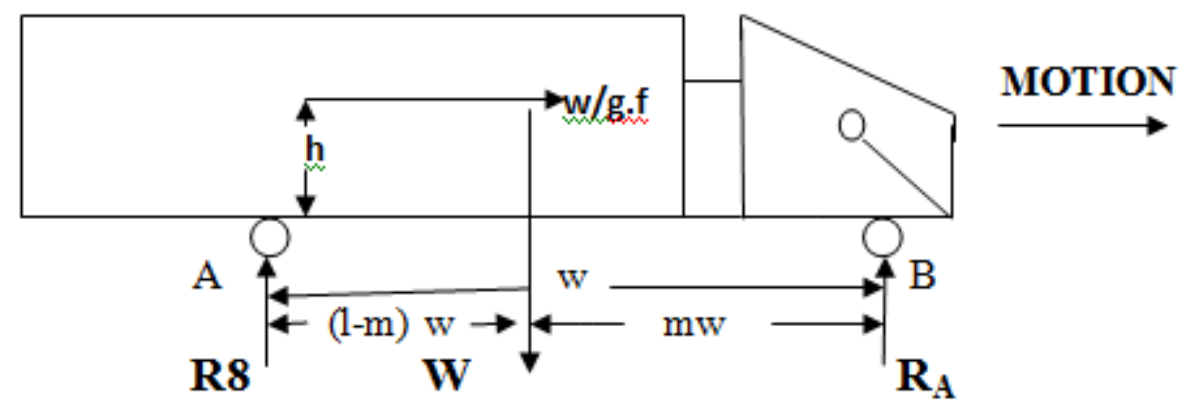

Where, $\mathrm{R}_{\mathrm{B}}{ }_{\mathrm{B}}$ is the dynamic reaction on the rear wheels.

\section{DISCUSSION :( TATA VEHICLES BRAKE SYSTEM)}

Therefore, $\mathrm{R}^{\mathbf{B}_{\mathrm{B}}}=$

W. m.w-w $\times f / g \times h$

W

$$
\frac{=\mathrm{W} \cdot \mathrm{mw}-\mathrm{W} \mu \mathrm{t} . \mathrm{h}}{\mathbf{W}}
$$

Therefore, percentage weight transferred from rear to front wheels:

$=\mathrm{R}_{\mathrm{B}}-\mathrm{R}_{\mathrm{B}^{1}} \times 100$

$=1 / \mathrm{w}\left[\frac{\mathrm{m} \cdot \mathrm{wW}}{5 \mathrm{~h}}-\frac{\mathrm{m} \cdot \mathrm{wW}}{5 \mathrm{~h}}+\frac{\mathrm{W} \mu \mathrm{th}}{5 \mathrm{~h}}\right] \times 100$

$=\mu \mathrm{t} / 5=100$,

$=0.7 / 5 \times 100$,

$=14 \%$

\subsection{Brake Circuit:}

Brake circuit is consists by following:

1. Compressor,

2. Unloaded Valve,

3. Reservoir,

4. Tank Valve,

5. Tandom Master Cylinder,

6. Regulator Valve,

7. Exhaust Brake Valve,

8. Exhaust Brake Cylinder.

9. Pressure Gauge,

10. Pilot Valve,

11. Spring Brake Chamber,

12. Front Wheel Cylinder,

13. . Rear Wheel Cylinder,

14. Drain Plug, etc.

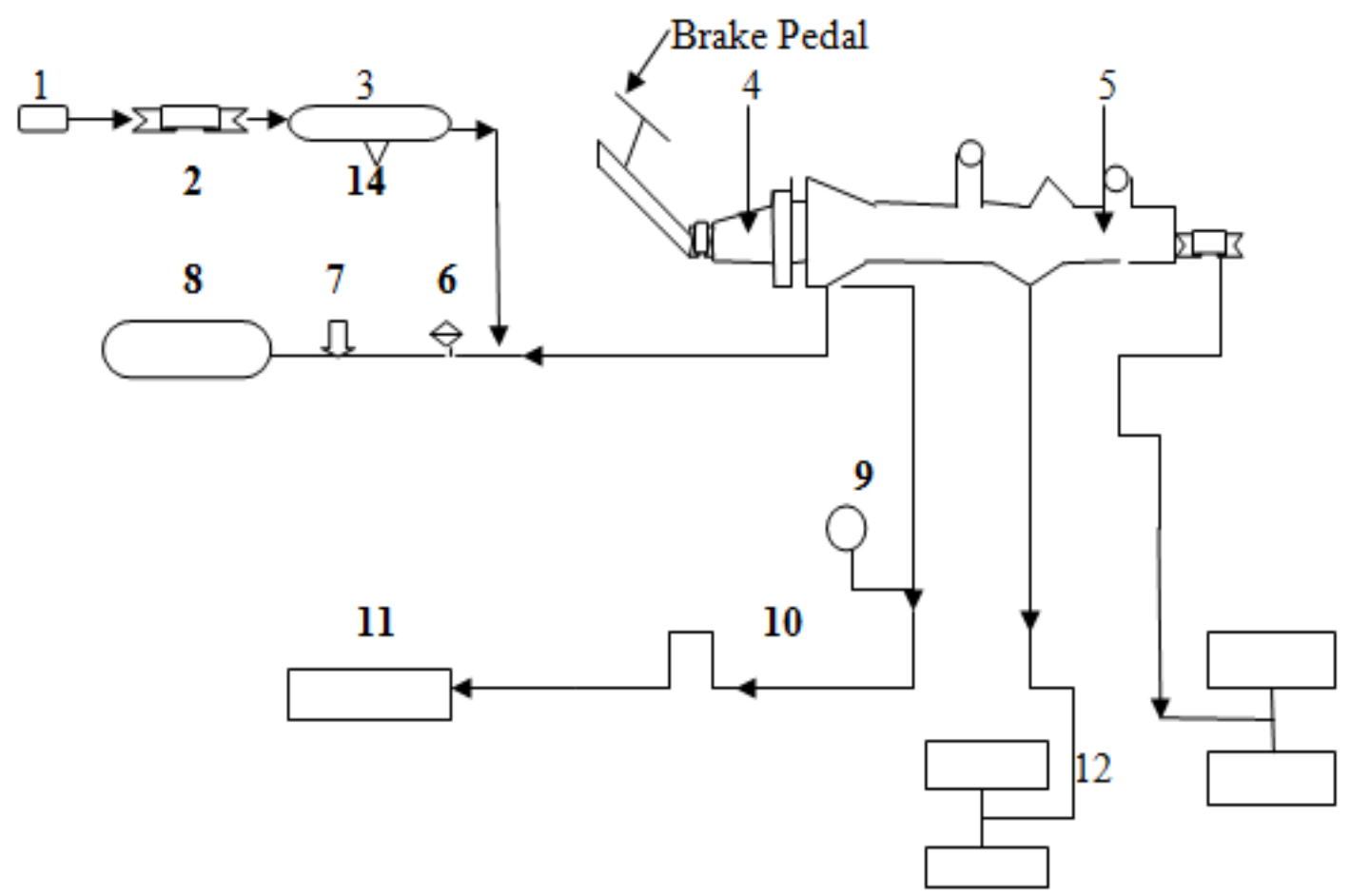

Fig: Brake Circuit Diagram: 


\subsection{Service Brake:}

Service brake is a good and confidence brake system in terms of Safety. Hydraulic brake system is operated by atmosphere air. These airs are operated of Air buster and Tandom Master cylinder, where by the front and rear wheel cylinder pressure, the hydraulic brake is working into the various points and both lines has separate lines. The main advantages from these two lines are that if one line does not working properly, another line is may working for the emergency application of the brake.

\subsection{Parking Brake:}

Need of parking brake, while vehicles on the parking mode. The parking brake is connected to the rear wheel to the smooth function, while the vehicle is simple load for parking. The main characteristic of the parking brake, if brake circuit does not working or lesser Air is available, that moment the parking brake is automatically connected to the rear wheel and audio sound would be coming for the driver intimation.

\subsection{Engine Exhaust Brake:}

Exhaust brake system is a suitable brake system, while the vehicle climbing on the hilly area. This system directly controlled the wear and tear on tyre as well as excessive heat. The main components of exhaust brake system:

(a) Air Compressor: It is located near the engine, and driven by camshaft which is connecting each other's and air is available in this compressor.

(b) Unloaded valve: This valve is working the following ways :

- Air is filtering, which are coming from the Compressor.

- Air controlled by Air Pressure,

- Air does not return to the compressor due to unloaded valve, etc.

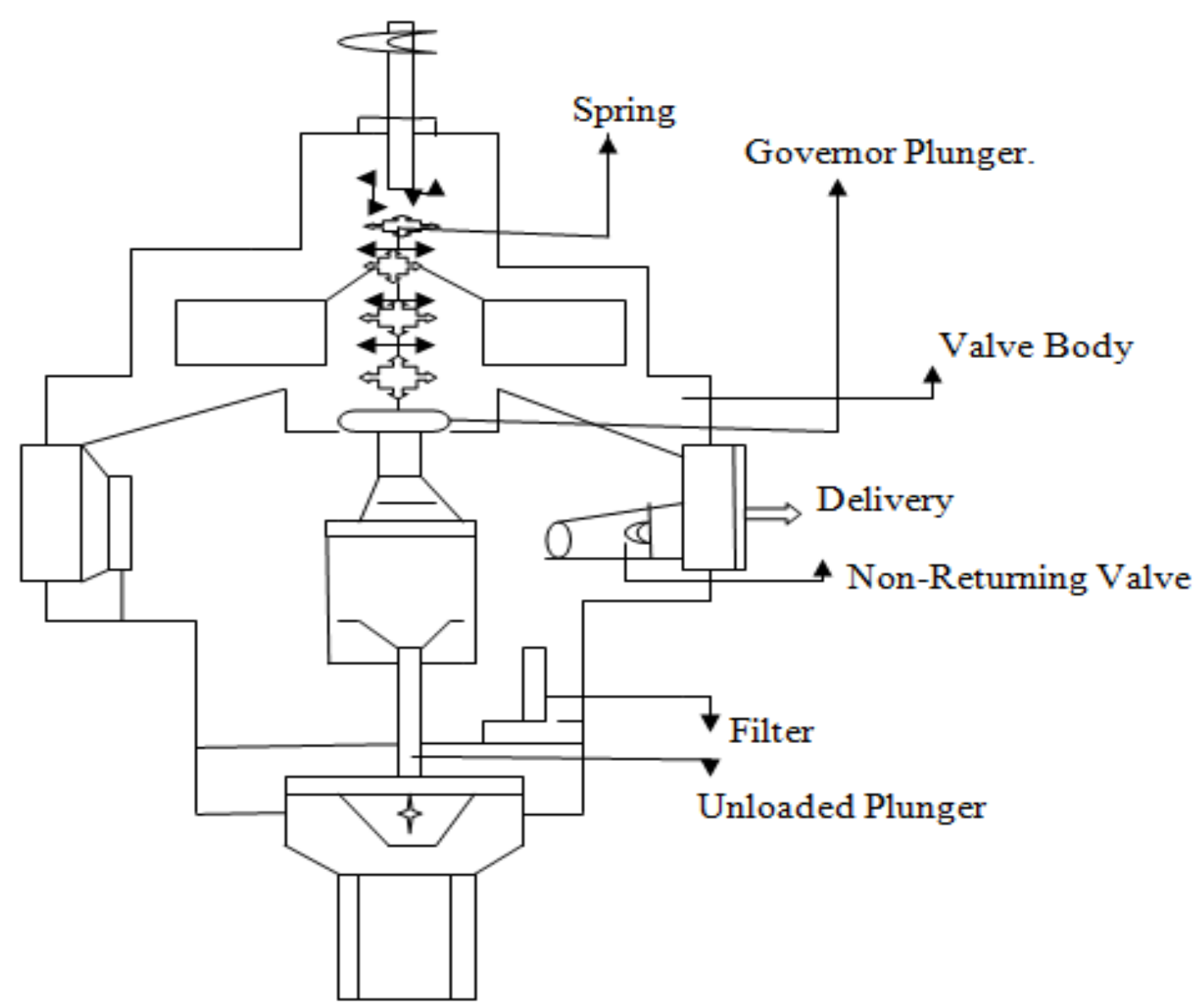

Fig: Unloaded Valve

Broadly, automotive brake systems are classified as:

1. Drum Brakes.

2. Disc Brakes.

\subsubsection{Drum Brake}

In an automobiles, the wheel is attached to an auxiliary wheel is called drum and brake shoes are contact on drum by means of application of brake pedal. Drum brake is consists by:

1. Internal Expanding

2. External Expanding. 
Internal expanding brake system is consisting by brake shoes and contacts the rotating drum, while brake pedal is applied. External expanding brake system contact to make contact with the rotating drum.

\subsubsection{Construction of Drum Brakes:}

Drum brake is consisting by:
i). Brake Drum.
ii) CAM,
iii) Brake lining,
iv) Return spring,
v). Anchor pin,
vi) Fixed wheel cylinder. Etc.

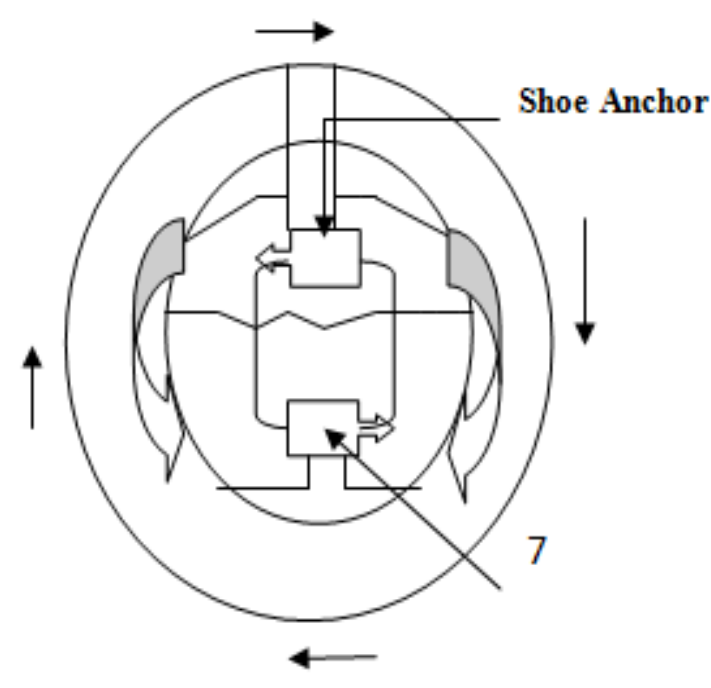

(b)

1. Brake drum, 2. CAM, 3. Brake lining, 4. Return Spring, 5. Anchor pin, 6. Fixed wheel cylinder, 7. Fixed wheel cylinder

\section{TYPE OF DATA}

\subsection{Parking Brake of Maruti Vehicles:}

Pull the parking brake lever all the way by one hand and see that he rear wheels are completely broken and not the notches traveled by hand lever. In case the lever move more than 3 notches rear brake shoe require adjusting as explained in brake shoe and drum clearance if the parking brake lever still moves by 3 notches and wheels are not braked than adjust the parking brake cable through adjusting nut.

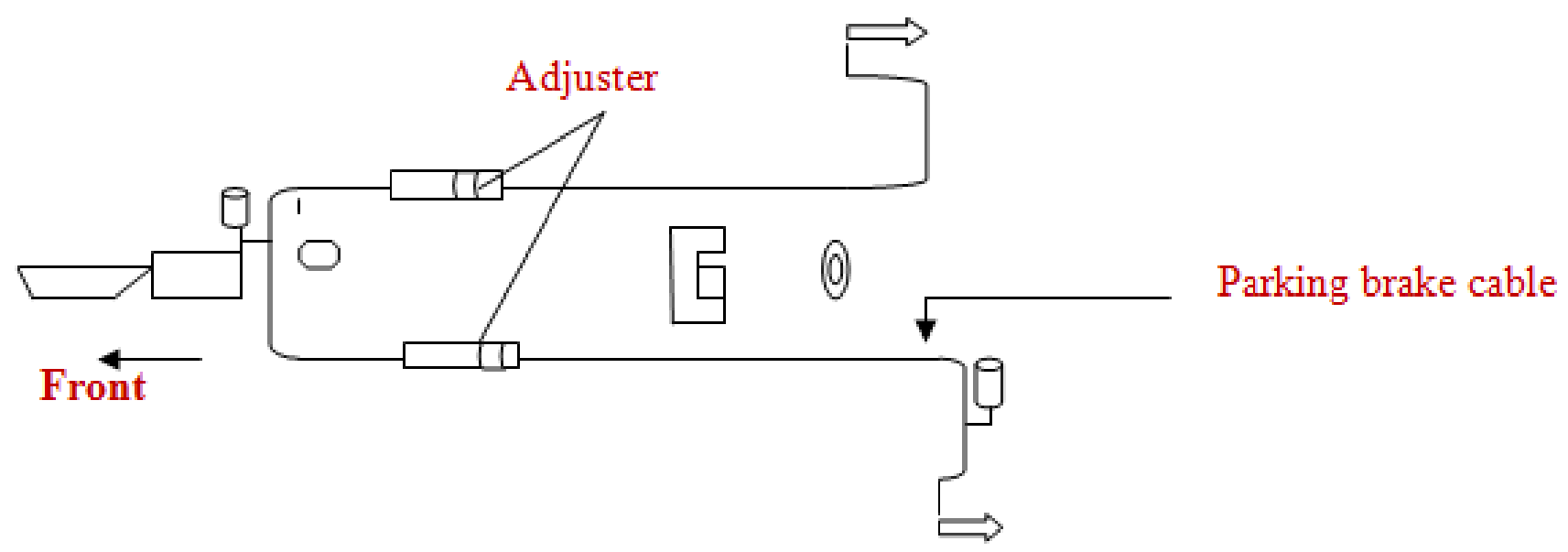

Fig: Parking brake adjuster in Maruti 


\section{CONCLUSION}

\subsection{Requirements of a Good Braking System:}

1. Application of brakes should bring the vehicle to a relatively quick stop on any type of road - wet, dry, even, uneven, uphill or downhill. The vehicle may be at any speed, laden or unladen.

2. The brakes should work equally well, fair or on bad roads.

3. Pedal effort applied by the driver should not be more so as not to strain the driver.

4. A separate mechanical brake is required to hold the vehicle in position on a gradient.

5. The braking system should not involve any noise or drift the vehicle away from its desired path.

6. While brakes going to applied, should not disturb steering geometry.

7. When brakes are applied, the vehicle should not pull to one side. Etc

\subsection{Advantage of Disc Brakes Systems}

1. Drum brake is a very simple design.

2. The maintenance and production is very cheaper.

3. It runs cooler as the disc is fitted outside and is open not in drum blanketed by wheel rim as such brakes are more positive.

4. Easy to remove and refit as soon as possible.

5. Does not need to adjustment. The piston due to pressure of brake oil presses the pads, sand witching disc in between as such it is self adjusting. Etc.

\subsection{Disadvantage of Drum Brake:}

1. Need of higher brake pedal pressure to stopping the vehicle.

2. Wearing of brake pads on high level.

3. Does not function significantly parking brake attachment. etc.

\section{BIOGRAPHY}

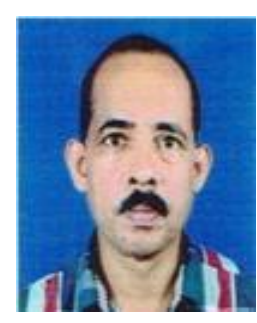

The author would like to thank the many people who helped and supported with this work. We received considerable tutorial information from UGC/NAAC/ICSSR sponsored National/International seminars /conferences and Course material from NCLM, Chennai with Management Development programme in XLRI and Executive Development programme in IIM Bangalore respectively. The author as Engineering Graduate, MBA along with Ph.D. in automobile engineering from International University, Washington, USA/2001 and Published numbers of research paper/projects completed i.e.

1. UGC sponsored national seminar: 85 Nos.

2. NAAC sponsored national seminar: 05 Nos.

3. CTE International Conference: 05 Nos

4. Guwahati University/Dibrugarh University/Assam University/ Tezpur University/ Assam Agricultural
university/UST, Shillong/ Institution of Engineers, etc National/International seminar/ Conference. : 40 Nos.

5. SAE International Conference/Exposition i.e. USA/France: 07 Nos.

6. Recipient of BOLT Award from Air India Ltd, Mumbai etc:

7. Publication of Books:07 Nos.

\section{REFERENCES}

[1]. Basic Auto motive engineering by Prof. C.P. Nakra, India.

[2]. Automotive Design problem by K M Agrawal, India.

[3]. Proceeding of SAE 2000 India Mobility Conference

[4]. Service Manual of Brakes India.

[5]. Service Manual of Telco.

[6]. Service Manual of Maruti.

[7]. Course materials in Telco workshop Manager Training Programme in Jamshedpur, 1992. Reference No. 8805 7706427

\section{DEFINITION/ ACRONYMS /ABBREVIATION:}

\section{Definition:}

Brake Horse Power: It is a unit for measuring power unit.

Brake Lining : Woven material mostly of asbestos or other heat resistant materials, applied to brake shoes and brake bands to produce friction.

Brake Shoe: A metal casting fitted in the brake drum of the wheel and pressed against the wheel to secure braking action.

Master Cylinder : A device in the braking or clutch system to develop hydraulic pressure in the pipe lines which lead to brake shoe or clutch.

CAM : A revolving eccentric which changes rotary motion into reciprocating motion.

\section{Acronyms /Abbreviation:}

DAOH: Dual Air Overhead Brake.

LCV: Light Commercial Vehicle,

HCV: Heavy Commercial Vehicle. 